$\xi=-1$

\title{
Automotive CVT sheave development using complex forging processes
}

\author{
Wen Kun Peng ${ }^{1}$, Sung-Young Park ${ }^{2}$ * \\ ${ }^{1}$ Department of Mechanical Engineering, Graduated School, Kongju National University, 1223-24, Cheonandaero, Budae-dong, \\ Seobuk-gu, Cheonan-si, Chungnam, 31080 KOREA \\ ${ }^{2}$ Div. of Mechanical and Automotive Engineering, Kongju National University, 1223-24, Cheonandaero, Budae-dong, Seobukgu, \\ Cheonan-si, Chungnam, 31080 KOREA \\ *Corresponding author E-mail: sungyoung@kongju.ac.kr
}

\begin{abstract}
Background/Objectives: In this study, we developed a complex forging process to produce a sheave, which is a core part of CVT for automobiles, fabricated prototypes. The existing processes such as hot forging and the MCT machining process have disadvantages including excessive amounts of material cutting, number of processes, and processing time.

Methods/Statistical analysis: To overcome these shortcomings, in this study, a shape was created using hot forging and the shape was molded into a precision part using cold forging. A complex forging process was developed that enabled maximization of the metallographic density and reduction of material cutting quantity by applying a minimal number of processes. By conducting heat compression and tensile tests of the samples, we identified the physical properties of the material and used the commercial software Deform-3D to conduct a forging analysis.

Findings: Based on the analysis results, we designed a combined process of hot forging and cold forging and fabricated a mold and pilot products. The fabricated pilot products were evaluated using a metal flow test, an internal defect test, a surface roughness test, etc. According to the evaluation results, no significant defect was observed, and we therefore believe it is adequate for mass production.

Improvements/Applications: The complex forging method can reduce the use of material by approximately $15 \%$ compared with the hot forging and the MCT machining process. Through this study, we established a product development process using a high-precision complex forging technology.
\end{abstract}

Keywords: Complex Forging; Forming Analysis; CVT, Process Development; Mold.

\section{Introduction}

Examining the environmental changes in the automobile transmission field, the current market environment aspect can be characterized by polarization of demand, diversification of consumers' needs, pursuit of high quality, and no defect. In terms of a technology environment, the development of new transmissions for environmental-friendliness and efficiency improvement, the pursuits of IT convergence technology, globalized competition, and catch-up by latecomers are visibly apparent. Under fierce competition, 5-speed manual gears, 4-speed automatic gears, and belt-type Continuously Variable Transmission (CTV) was developed and has been used since the 1990s. In the 2000s, 6-speed manual gears, 5-speed automatic gears, and Torodial-type CTV were developed. Currently, a variety of [6] or above speed automatic gears, CVT, eCVT, DCT, AMT, and hybrid-exclusive transmissions are being developed as the next-generation transmissions [1].

CVT, also known as a stepless transmission, can change seamlessly through a continuous range of effective gear ratios. As it can operate the engine at the most efficient revolutions per minute (RPM) according to vehicle speed, CVT has been evaluated as having a high fuel efficiency [2-3].

The sheave, a core part of CVT, is manufactured using forging processes. The forging process is one of the oldest plastic working methods, and because it can be used for mass production of products with excellent mechanical properties, it has been significantly developed together with the automobile industry. As the automobile industry requires not only durability and high strength, but also high-precision parts, a need is growing for a molding method that can satisfy the needs for durability and high precision at the same time. To this end, various complex forging methods of hot forging as a basic fabrication process and cold forging for a high precision are currently used [4.5].

Hot forging involves forging a material by heating it to the temperature of the recrystallization point or above. Its advantages are a relatively smaller molding load and a large plastic deformation. However, due to poor mechanical properties, it can cause serious tearing and wear of the mold, and the dimensional precision can be significantly reduced in comparison with the cold forging process. In contrast, cold forging involves forging a material at room temperature or at a similar temperature, and its advantage is high dimensional precision. Due to its high dimensional precision, it can reduce the required number of processes by a significant level [6].

The existing sheave processing methods such as hot forging and MCT machining processes require an excessive amount of material cutting, an excessive number of processes, and excessive processing time. In contrast, a complex forging method can create a shape using hot forging and perform high precision molding using cold forging; its advantage is its ability to enhance durability and 
significantly reduce the amount of material cutting and processing time [7]. In this study, we utilized the features of both hot forging and cold forging and developed a complex forging process to fabricate a CVT sheave.

\section{Main content}

\subsection{Hot/cold complex forging process}

Figure 1 shows a diagram schematizing an ordinary forging process and a complex forging process. The ordinary forging process includes the MCT machining process and welding process. In contrast, the complex forging process does not involve the MCT machining process and welding process, because it uses a cold forging process to perform precision molding of the material. Through this, we found that it could reduce the per-unit production time by as much as $200 \%$ and reduce the amount of material cutting.

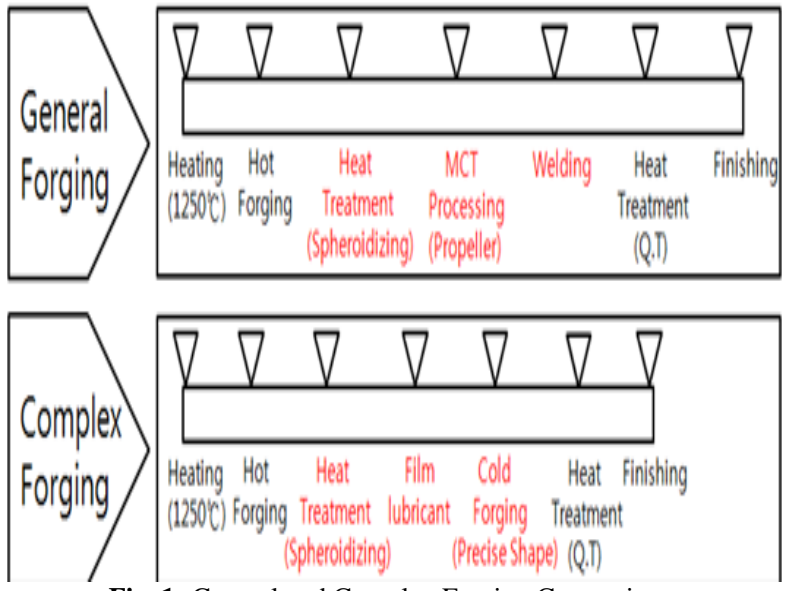

Fig. 1: General and Complex Forging Comparison.

\subsection{Physical property test of material}

\subsubsection{Hot compression test}

A hot compression test was conducted on Chromium molybdenum steel (15CrMo5) used as the material of the CVT sheave to identify the physical properties of the forging material in a hot forging condition. Through the molding analysis, samples were designed to have the maximum compression of $10 \mathrm{~mm}$ and bear approximately 15 tons under compression. Based on the analysis results, we fabricated cylinder-shaped samples with a diameter of $10 \mathrm{~mm}$ and a height of $15 \mathrm{~mm}$. Figure 2 shows the equipment and samples used for the hot compression test.
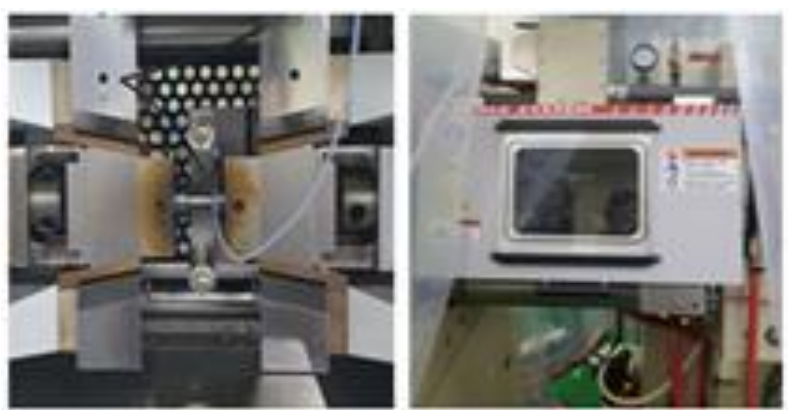
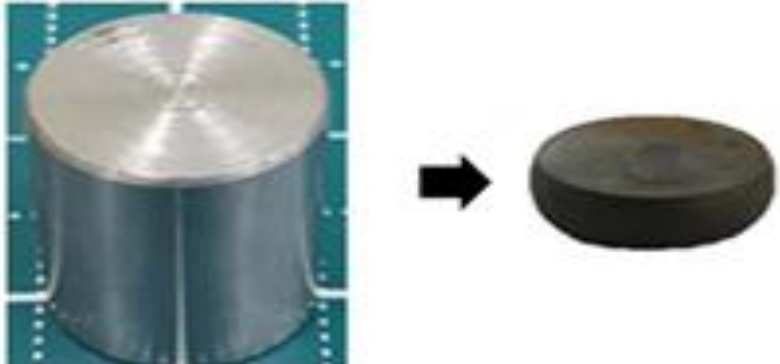

Fig. 2: Compressive Testing Machine and Samples.

The hot compression test was repeatedly conducted at temperatures of $700^{\circ} \mathrm{C}, 800^{\circ} \mathrm{C}$, and $1000^{\circ} \mathrm{C}$ under various strain rates of $0.1 / \mathrm{s}, 1 / \mathrm{s}$, and $5 / \mathrm{s}$, respectively. Data concerning loads and stresses were obtained through the hot compression test and the deformation characteristics of the material were also examined. A total of 22 samples were used for the hot compression test, and the compressive stress levels and deformation rates estimated by the test are shown in Figure 3.

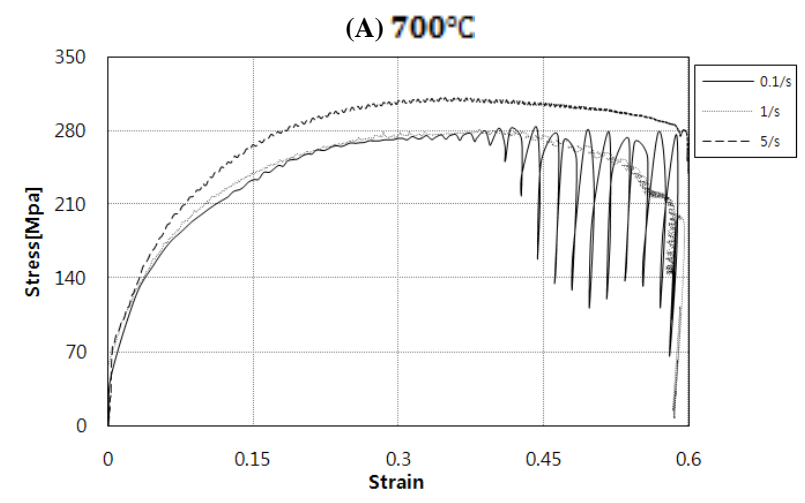

(B) $800^{\circ} \mathrm{C}$

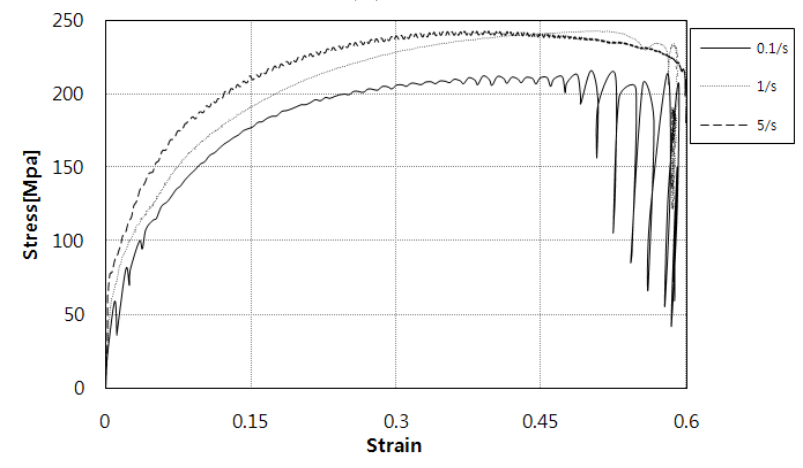

(C) $1000^{\circ} \mathrm{C}$

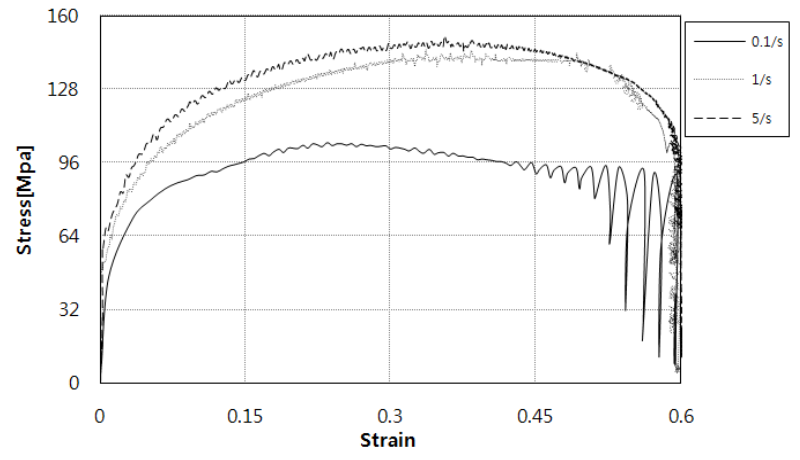

Fig. 3: Stress-Strain curve.

\subsubsection{Tension test}

The tension test was conducted to identify the basic physical properties of the sheave in cold and hot forging conditions. Samples were fabricated using the standard size of Korean Standard (KS) 
13 B. Figure 4 shows the equipment and samples used for the compression test.
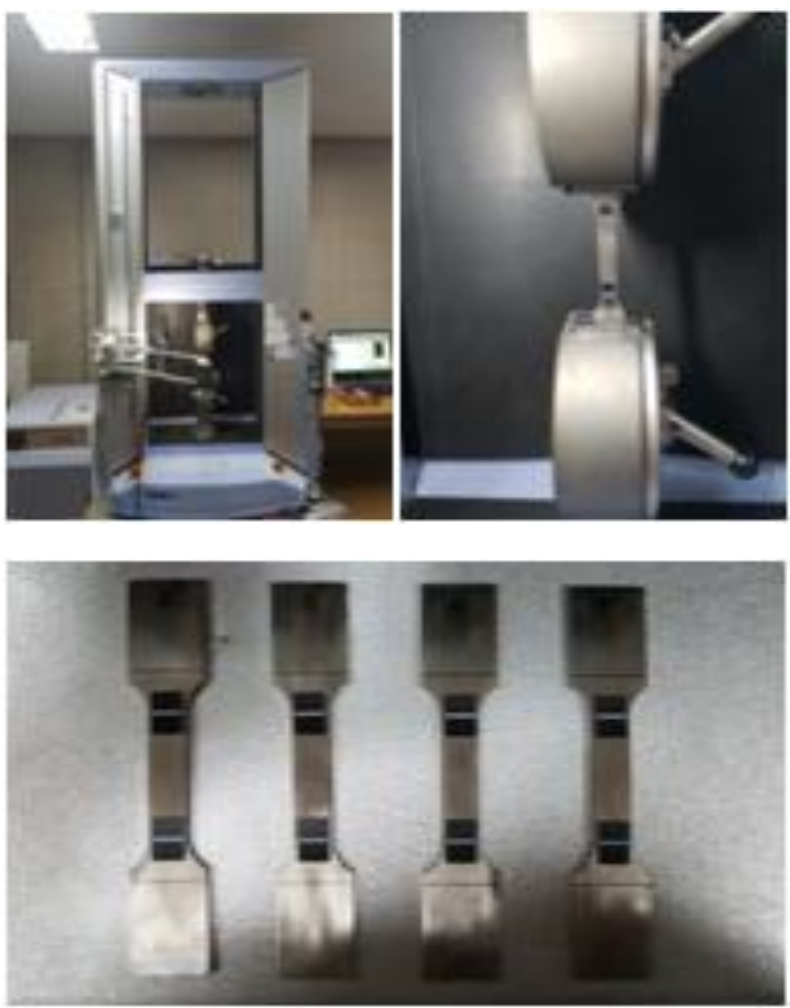

Fig. 4: Tension Testing Machine and Samples.

The multi-purpose tester by SHIMADZU was used, and a total of 5 samples were used for the tension test. The results of the tension test are shown in Figure5. The yield strength was measured at about $520 \mathrm{MPa}$ as an offset value of $0.2 \%$, and the ultimate tensile strength was about $690 \mathrm{MPa}$.

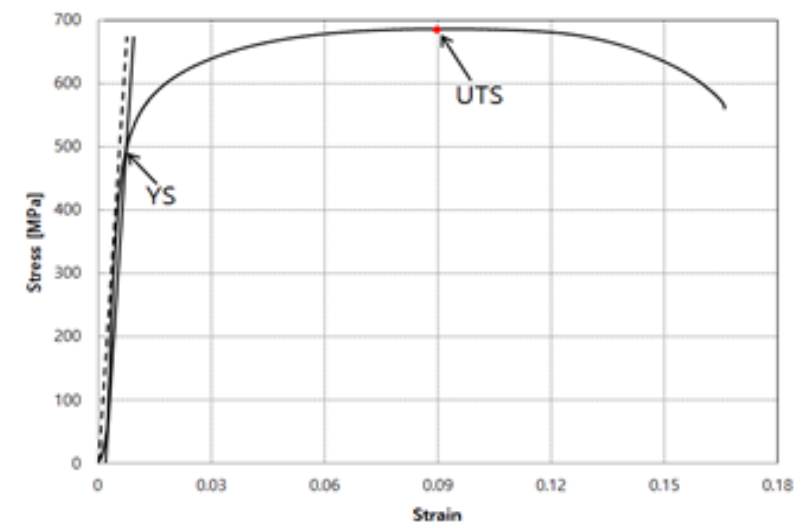

Fig. 5: Tension Test Result.

\subsection{Design and analysis of complex forging process}

The process design for the production of CVT sheaves was performed. Hot forging and cold forging were separately conducted. The forging molding analysis was conducted using the widely used software, 'Deform-3D' [8]. The hot forging process analysis was conducted on four steps including the piercing. The cold forging process was performed to improve dimensional precision, and the shape changes of each process are shown in Figure 6.

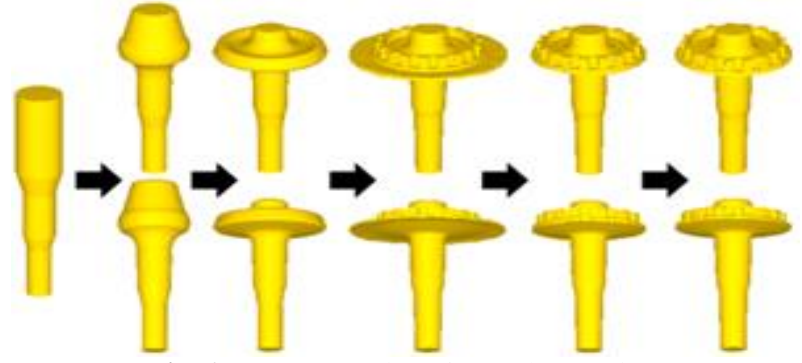

Fig. 6: Process Drawing of Complex Forging.

The hot forging molding analysis was conducted by applying the physical properties of the material obtained from the hot compression test to the analysis program. About 90,000 elements were involved in the hot forging process analysis. The hot forging analysis was carried out by descending the upper part of the mold after the material rested in the mold. Figure 7 shows a diagram of a hot forging mold assembly from stage 1 to stage 4 , and the $4^{\text {th }}$ stage of the hot forging analysis was the piercing process.

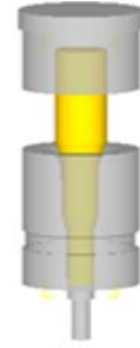

$1 \mathrm{st}$

station

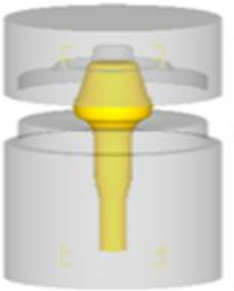

2nd

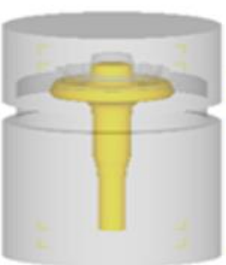

3rd

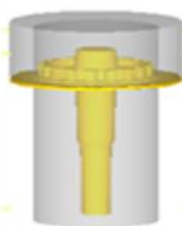

4th station
Fig. 7: Hot Forging Mold Assembly Drawing.

Figure 8 shows the analysis results of the 1 ststage hot forging, and the maximum compression stress acting on the material was measured at approximately $83 \mathrm{MPa}$. When the mold pressed onto the material, a compressive strain occurred, and high stress was measured at the deformed spot from the start of the deformation of the material.
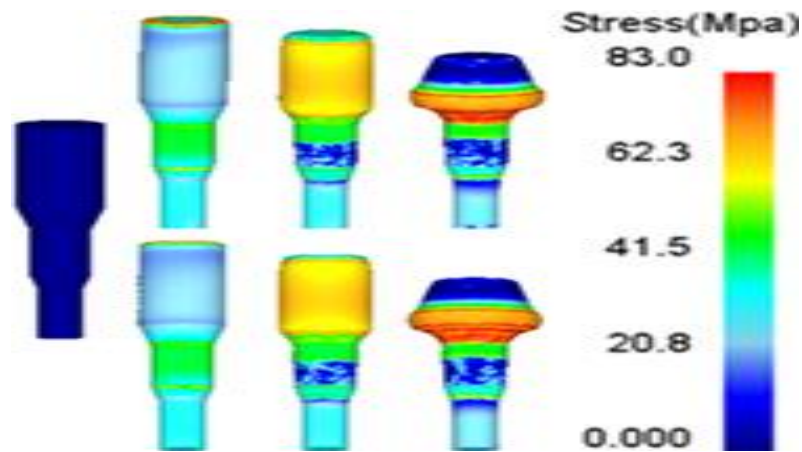

83.0

62.3

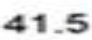

20.8

0.000

Fig. 8: First Station Hot Forging Stress Analysis Result.

Figure 9 shows the analysis results of the second stage hot forging, and the maximum compression stress acting on the material was measured as being approximately $170 \mathrm{MPa}$. In the early phase of analysis, high stress was measured in the upper part of the product, but as the analysis proceeded to the next phases, stress was concentrated in the middle or lower part. 


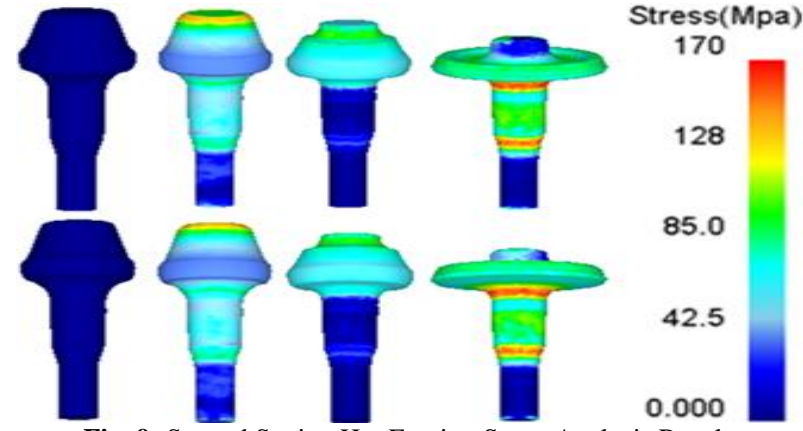

Fig. 9: Second Station Hot Forging Stress Analysis Result.

Figure 10 shows the analysis results of the third stage hot forging, and the maximum compression stress acting on the material was measured as being approximately $200 \mathrm{MPa}$. As the analysis proceeded, high stress acted in the middle part of the product, and as the stress was heavily concentrated on the part in which the shape of the gear was visible, the maximum compressive stress occurred on the edges of the gear teeth.

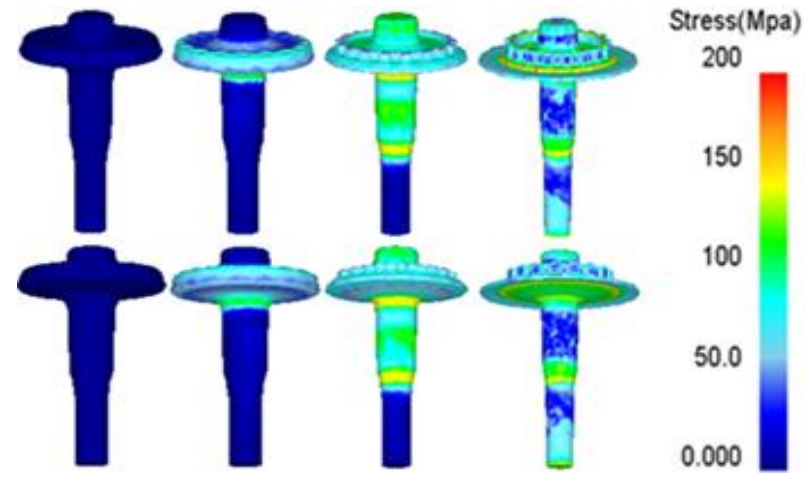

Fig. 10: Third Station Hot Forging Stress Analysis Result.

Figure 11 shows the results of the fourth stage hot forging (piercing) analysis, and the maximum compression stress acting on the material was measured at approximately $100 \mathrm{MPa}$. As compressive strain occurred when the mold was pressed onto the material, a high stress occurred in the piercing part of the product.

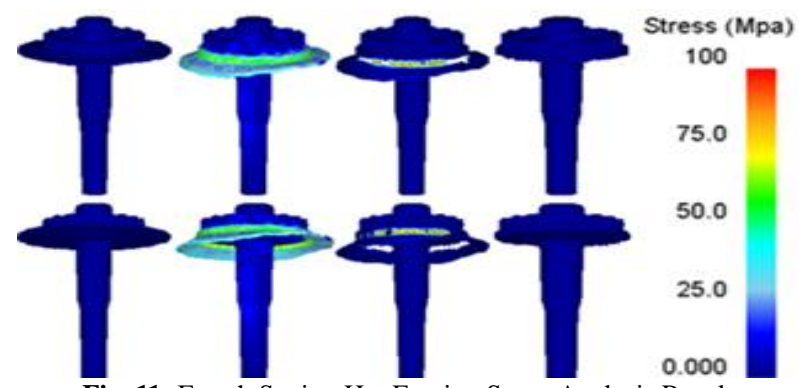

Fig. 11: Fourth Station Hot Forging Stress Analysis Result.

The cold forging molding analysis was conducted by applying the physical properties of the material obtained from the tension test to the analysis program. The number of elements used for the cold forging process analysis was estimated to be about 170,000. Similar to the hot forging process analysis, the analysis was carried out by descending the upper part of the mold after the material was rested in the mold. Figure 12 shows a diagram of the cold forging mold assembly.

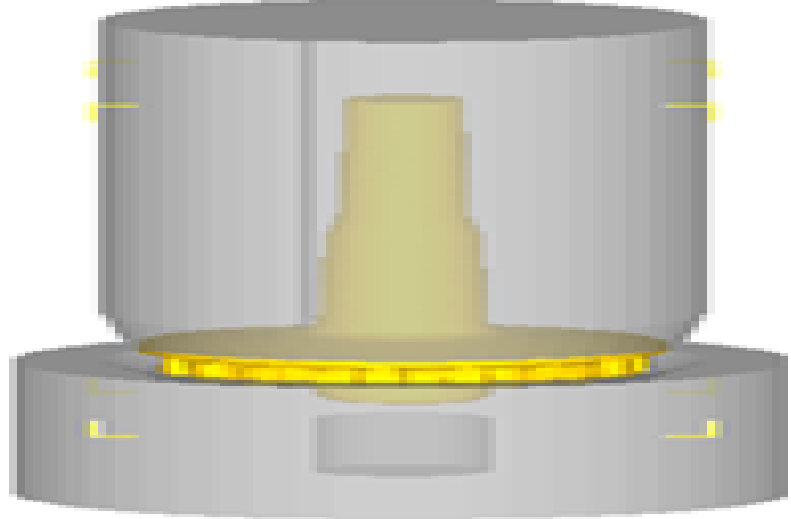

Fig. 12: Cold Forging Mold Assembly Drawing.

Figure 13 shows the analysis results of the cold forging, which met the dimensional requirements of the final shape. The maximum compression stress acting on the material was measured to be approximately $900 \mathrm{MPa}$. According to the overall analysis results, while very low stress occurred in the early stage of the analysis, as the analysis proceeded further, very high stress occurred in the tooth form part. As the stress occurring due to deformation was higher than the yielding stress, it was believed that the material could be molded into a good shape in the cold forging process.
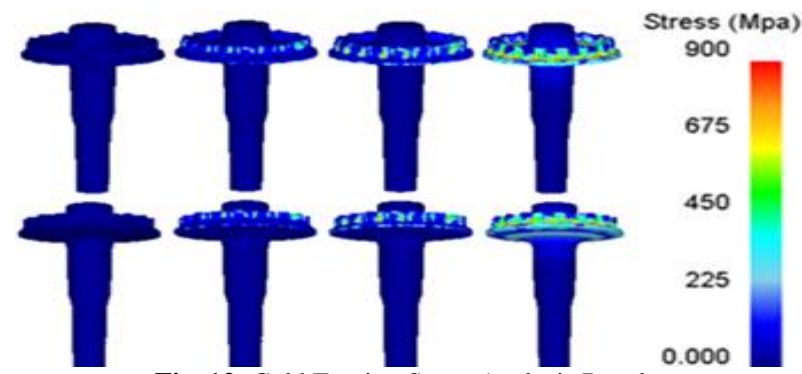

Fig. 13: Cold Forging Stress Analysis Result.

\subsection{Fabrication of CVT sheave pilot products}

Through the analysis, the molds for hot forging and cold forging were fabricated, and pilot products were then produced. Figure 14 shows the hot forging mold and pilot products. The hog forging mold was fabricated using SKD-61 material. Figure 15 shows the under fill phenomenon caused by air pockets occurring during hot forging. To solve this problem, air holes were created in the tooth form part of the upper mold.
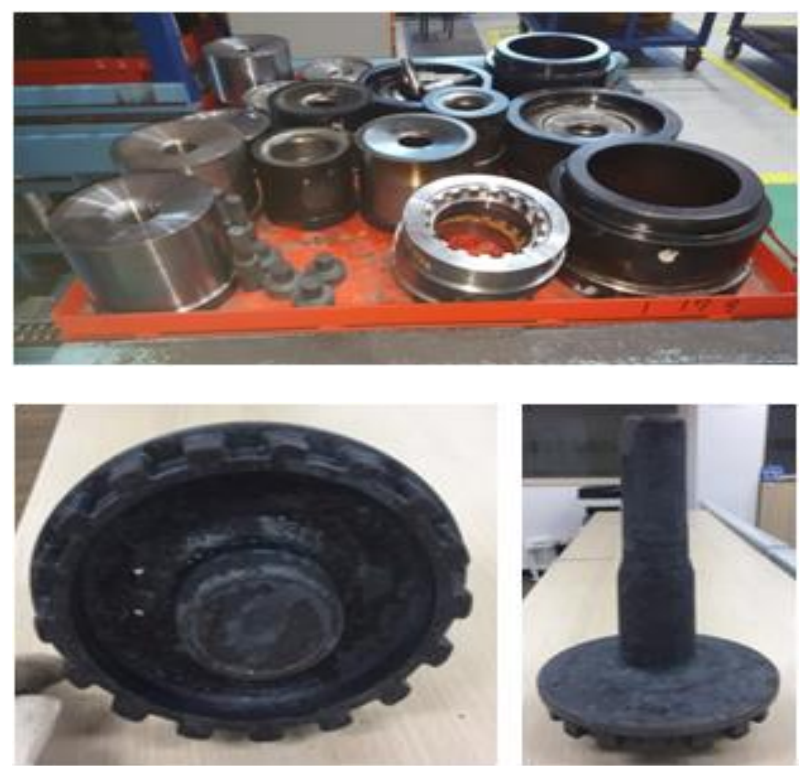

Fig. 14: Hot Forging Press Mold and Prototype. 


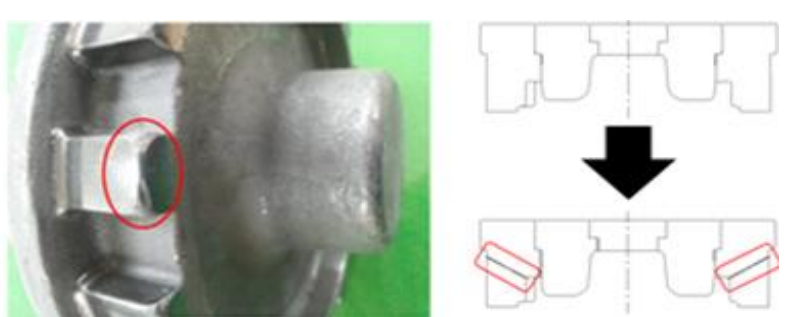

Fig. 15: Fault and Measurements.

Figure 16 shows the cold forging mold and pilot products. The cold forging was performed in consideration of the high stress occurring during extrusion. The tooth form part of the mold was fabricated using SKH-51 material. Figure 17 shows defects such as flash lapping on the bottom of the teeth and tooth form tearing due to the application of excessive cold sizing $(0.3 \mathrm{~mm})$. To solve this problem, the analysis was repeated again with the reduced cold sizing from $0.3 \mathrm{~mm}$ to $0.15 \mathrm{~mm}$.
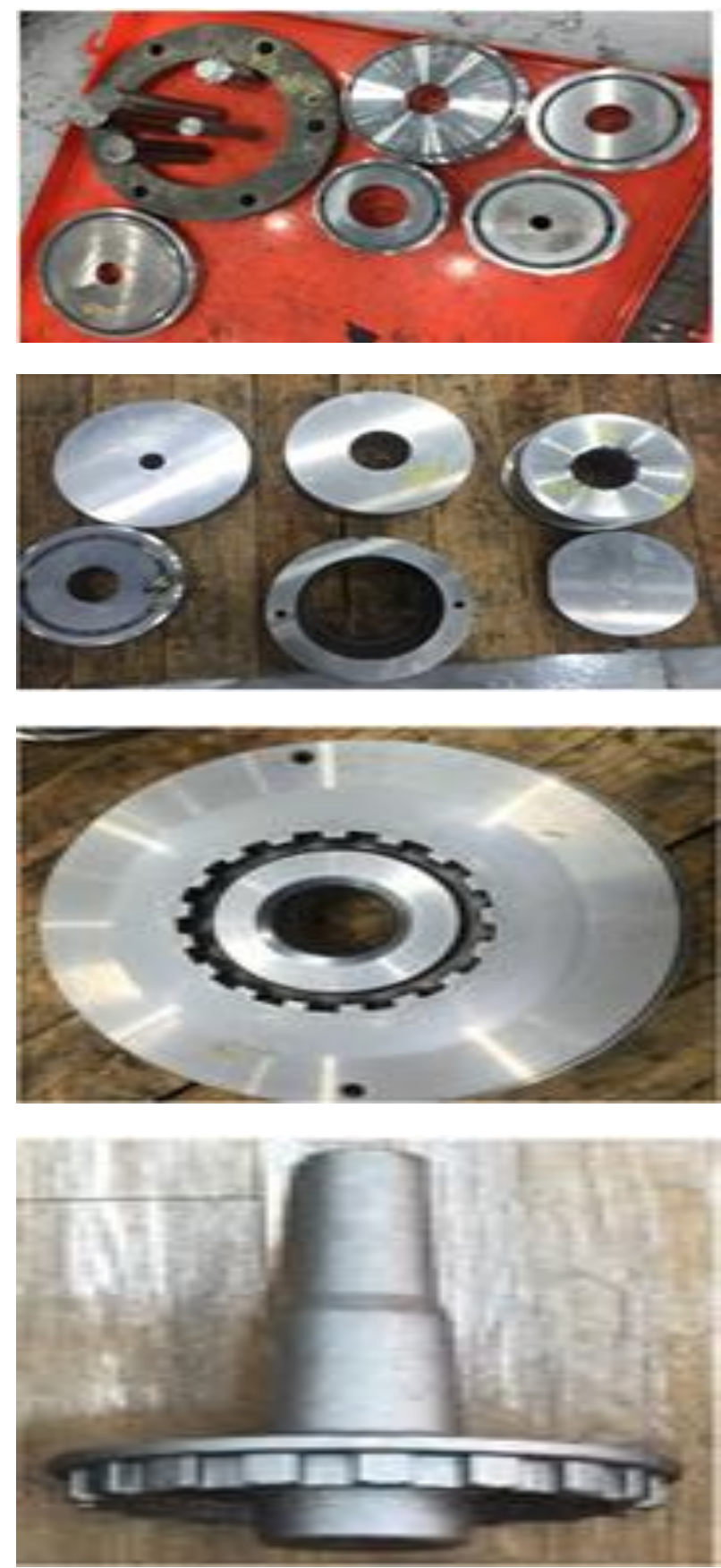

Fig. 16: Cold Forging Press Mold and Prototype.

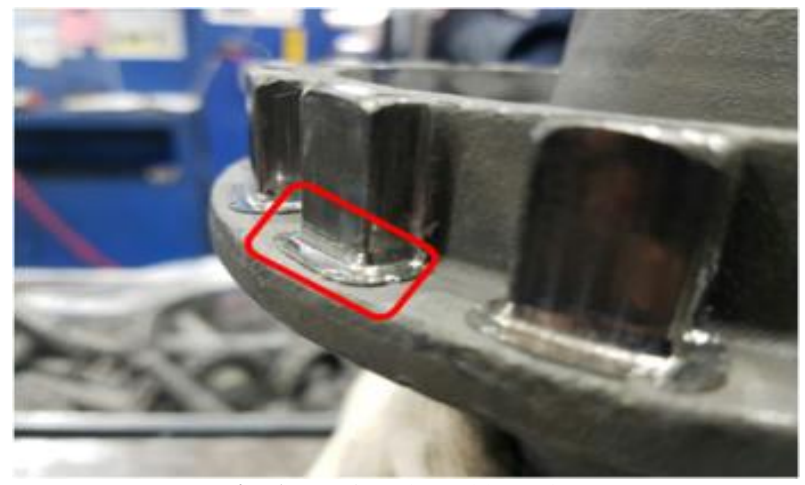

Fig. 17: Defects in Cold Forging.

\subsection{Evaluation of CVT sheave pilot products}

\subsubsection{Shear line test}

Figure 18 shows the measurement results of the shear line of pilot products fabricated using the suggested complex forging method. According to the measurement results, no spots were found with overlapping and severed shear lines.

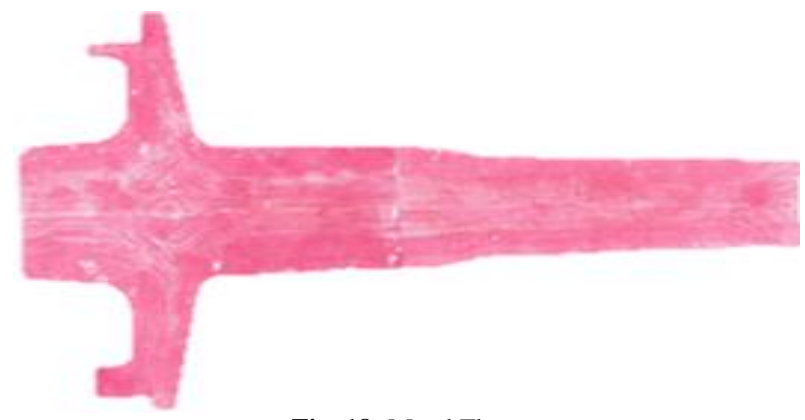

Fig. 18: Metal Flow.

\subsubsection{Inspection for internal defects}

The internal defect and ingredient analysis was conducted by fabricating SEM samples. The samples were collected and fabricated by polishing to check for cracks and pores inside the fabricated sheave as shown in figure 19.
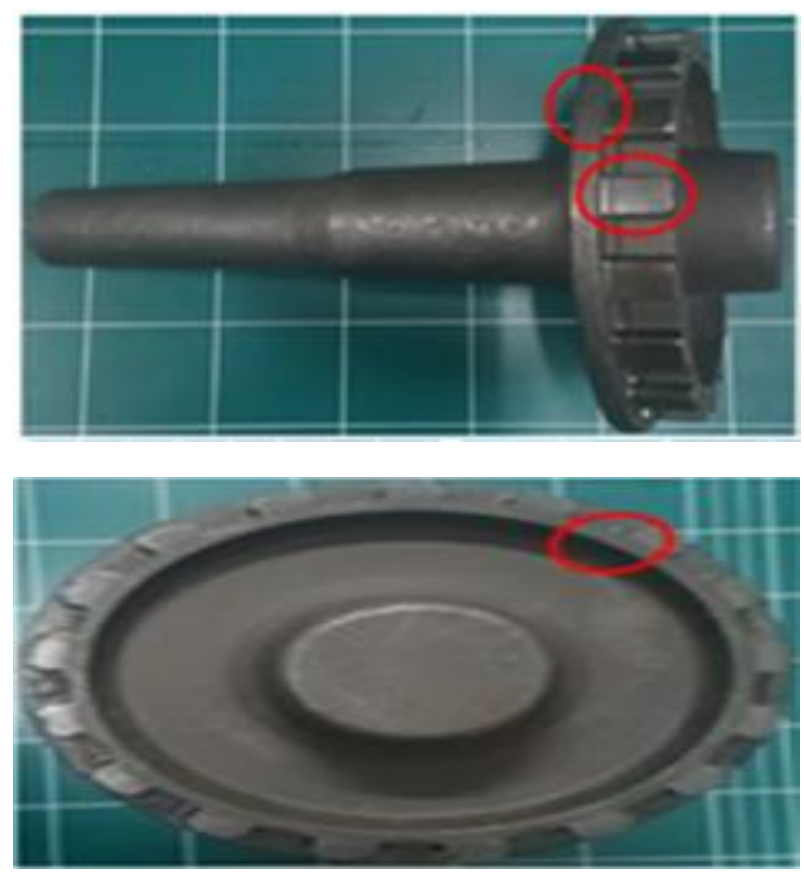

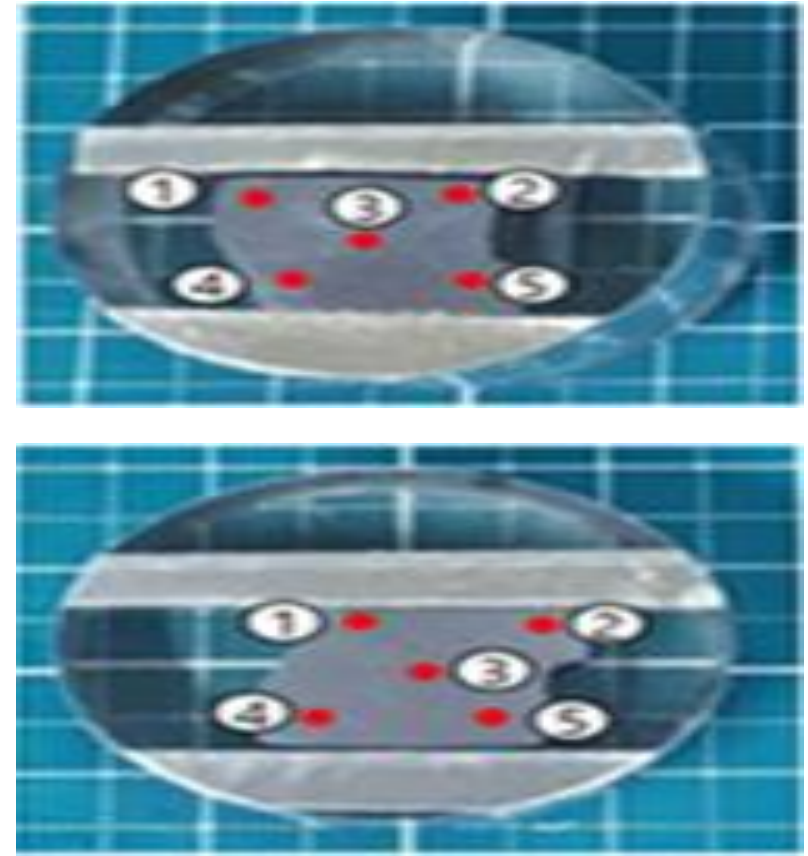

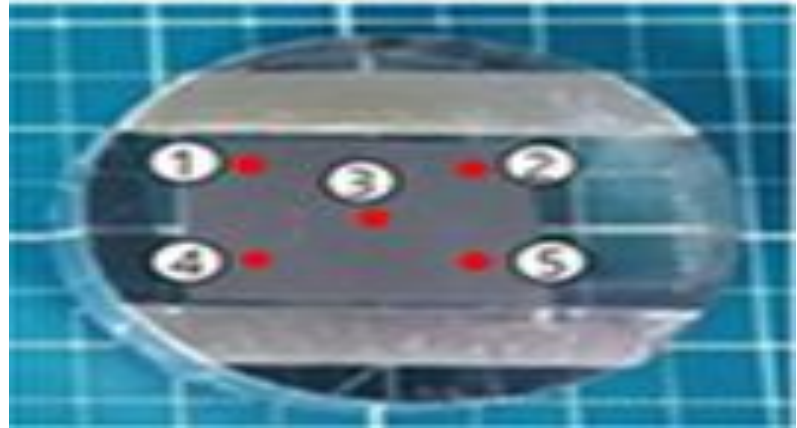

Fig. 19: Prototype Cutting Position and Specimen.

In the SEM imaging, 5 points of three incised samples were designated for imaging and were magnified at 1:3,000. No internal defects with pores of more than $50 \mu \mathrm{m}$ or cracks were detected inside the samples. Figure 20 shows the images of the designated spots of each sample.

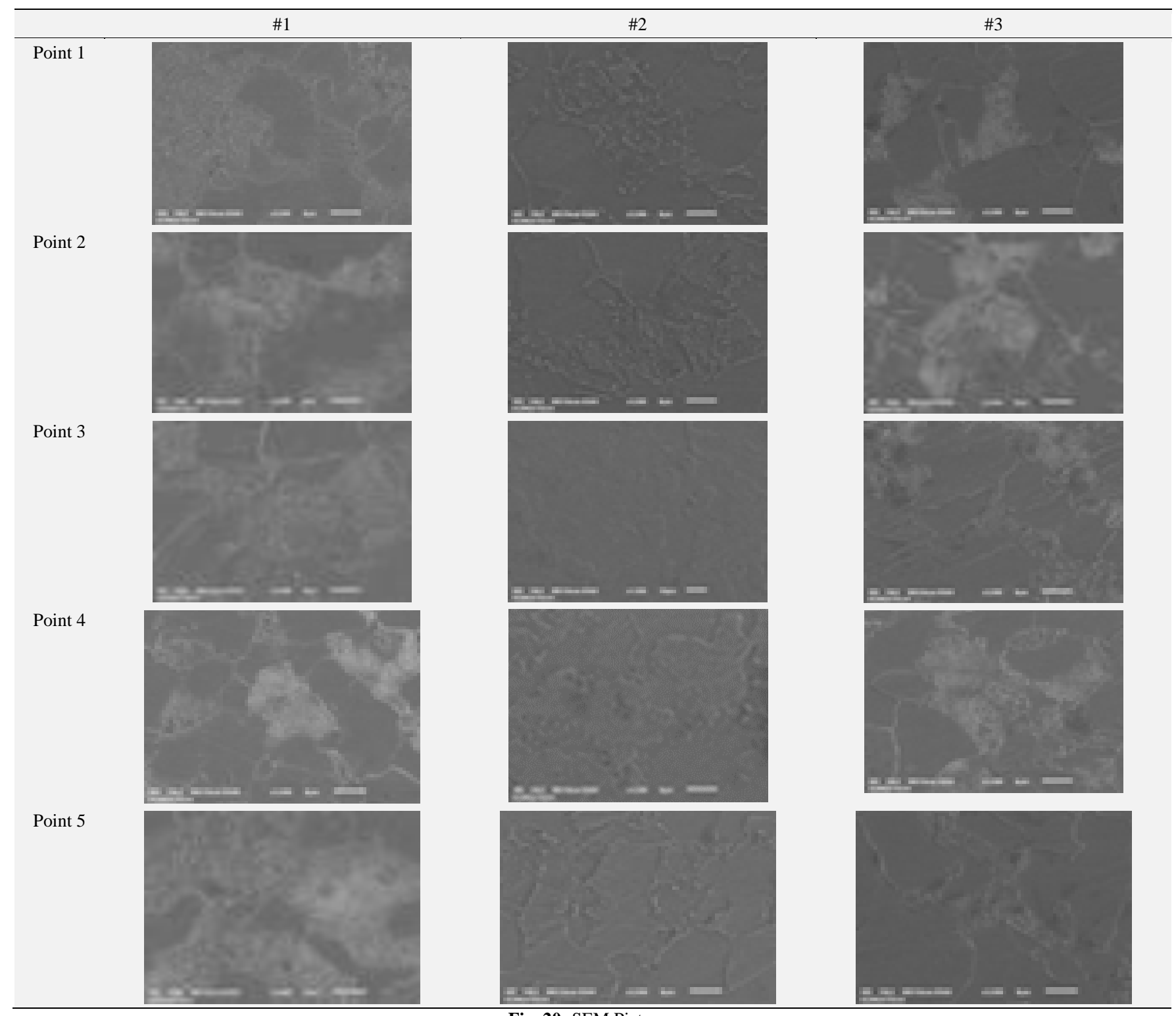

Fig. 20: SEM Pictures. 


\subsubsection{Weight measurement}

Table 1 shows the weights before and after the development of the suggested complex forging method. The weight measurement was conducted a total of three times using Digital Electronic Scales. The average material reduction was measured to be $1.21 \mathrm{~kg}$ per unit, a $15 \%$ reduction compared with the existing methods.

Table 1: Weight Measurement before and after Complex Forging Processes Development

\begin{tabular}{lll}
\hline & Measured Value $(\mathrm{kg})$ & \\
\hline Material No. & General Forging & Complex Forging \\
1 & 7.92 & 6.74 \\
2 & 7.96 & 6.72 \\
3 & 7.94 & 6.74 \\
Average & 7.94 & 6.73 \\
\hline
\end{tabular}

\subsubsection{Tooth surface roughness measurement}

Table 2 shows the measurement values of the tooth form surface roughness. The tooth form surface roughness was measured at 5 points for each sample. The average surface roughness was measured at a satisfactory level of $1.315 \mathrm{Rz}$. Figure 21 shows the measurement points of the final pilot products to estimate surface roughness.

Table 2: Tooth Form Surface Roughness Measurement (Unit: Rz)

\begin{tabular}{lllllll}
\hline Point & 1 & 2 & 3 & 4 & 5 & Average \\
\hline $\begin{array}{l}\text { Measured } \\
\text { Value }\end{array}$ & 1.18 & 1.41 & 1.04 & 1.29 & 1.66 & 1.315 \\
\hline
\end{tabular}
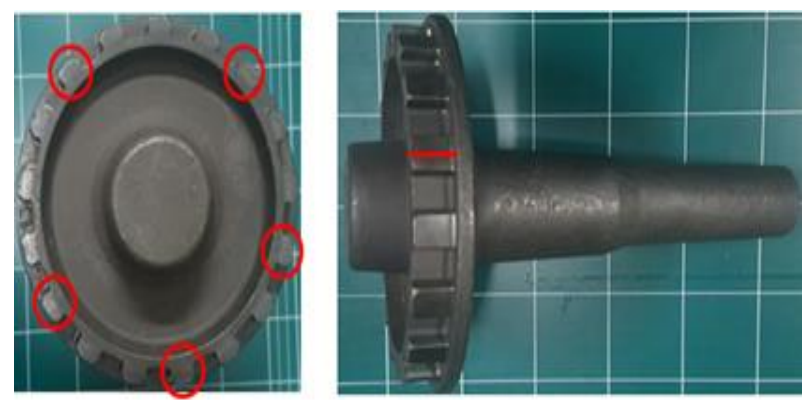

Fig. 21: Surface Roughness Measurement of the Final Prototype

\section{Conclusion}

In this study, a complex forging process was developed for the fabrication of sheaves, which are a core part of CVT. From the molding analysis, the complex forging process was developed, and the molds and pilot products were fabricated and evaluated. The conclusions to the study are as follows:

1) In this study, a development process was established from a physical property evaluation to pilot product fabrication of a CVT sheave. The development of a complex forging process made it possible to reduce the number of processes and processing time compared with the previous processes. The developed forging process reduced the material use by approximately $15 \%$ compared to the existing processes of hot forging + MCT machining + welding. The omission of the machining processes is expected to contribute to reducing the unit production time.

2) Through the analysis of the complex forging process, the molding conditions and processes were developed. The hot forging process was conducted in 4 stages, and the maximum compression stress and occurrence spots were examined. According to the results of the cold forging process, stress occurred at an early stage of the analysis, but as the analysis proceeded further, very high stress occurred in the tooth form part of the mold. The maximum compression stress was measured to be approximately $900 \mathrm{MPa}$.

3) In the hot forging process, under-fills were observed, caused by the occurrence of air pockets. To solve this problem, air holes were made in the tooth form part of the upper mold. In the cold forging process, the application of an excessive amount of cold sizing caused flash lapping on the bottom of the tooth form part and tooth tearing. To solve this problem, the sizing amount was reduced.

4) The molds for hot forging, cold forging, and pilot products were fabricated, and to evaluate the pilot products, the shear line test, internal defect test, weight measurement, and surface roughness measurement were conducted. Since the measurement, results showed no significant problem, we believe that the complex forging process can be applied for mass production.

The complex forging process developed in this study is a technology that can be widely applied to the production of other parts, and it is believed that it can contribute to reducing material use and the number of required processes.

\section{References}

[1] H. C. Shin, B. H. Lee, J. H. Jeong, Y. G. Choe, Green auto chassis. GoldenBell, the Third Revised Edition, pp. 45- 48, 2013.

[2] S. H. Lee, W. J. Chung, E. K. Hong, M. S. Shin, Y. M. Kim, K. D. Ryu, Study on fuel economy improvement of CVT for mid-size vehicle. The Korean Society of Automotive Engineers, pp. 238-242, 2012.

[3] J. Y. Kim, Y. I. Park, F. C. Park, J. M. Lee, On the Development and Application of the Spheriacl CVT. The Korean Society of Mechanical Engineers, pp. 690-695, 2000.

[4] S. J. Jang, B. Y. Jun, S. M. Jang, M. S. Joun, H. K. Moon, H. S. Sung, M. H. Heo, Development of Hot and Cold Combined Forging Process for a One-Way Clutch Bearing Outer Race. The Korean Society for Technology of Plasticity, pp. 441-444, 2009.

[5] E. J. Gwak, W. H. Ju, H. S. Moon, E. C. Lee, S. Y. Park, Complex Forging Processes Development of Core Part in One-way Clutch. The Korean Society for Technology of Plasticity, pp. 185-187, 2015.

[6] M. S. Joun, H. K. Moon, M. C. Lee, D. Y. Suh, Finite Element Analysis of Compound Forging Processes. Korean Society for Precision Engineering, pp. 546-550, 1996.

[7] J. H. Nam, S. H. Jung, T. W. Jung, Y. S. Lee, Study on New Process for Precision Forging of Helical Gear. The Korean Society for Technology of Plasticity, pp. 107-110, 2010.

[8] DEFORM User's Manual V11.0, Scientific Forming Technologies Cooperation, 2016. 